\title{
Urdimento
}

Revista de Estudos em Artes Cênicas

E-ISSN: 2358.6958

\section{Transfiguras espaciais-temporais. Espaços de finitude em teatro e performance da atualidade}

\author{
Nikolaus Müller-Schöll
}

Tradução: Stephan Arnulf Baumgärtel e Talita Corrêa

\section{Para citar este artigo:}

MÜLLER-SCHÖLL, Nikolaus. Transfiguras espaciaistemporais. Espaços de finitude em teatro e performance da atualidade. Trad. Stephan Baumgärtel e Talita Corrêa. Urdimento, Florianópolis, v. 2, n. 38, ago./set. 2020.

DOI: http:/dx.doi.org/10.5965/14145731023820200046 
Transfiguras espaciais-temporais. Espaços de finitude em teatro e performance da atualidade

Nikolaus Müller-Schöll²

Tradução: Stephan Arnulf Baumgärtel ${ }^{3}$ e Talita Corrêa ${ }^{4}$

\begin{abstract}
Resumo
A partir de uma crítica de concepções arquitetônicas dos espaços teatrais e contextualizando suas transformações numa perspectiva histórico-cultural, o artigo discute maneiras como sair ou não sair do dispositivo de espaço à italiano. Discute até que ponto as perturbações e desafirmações do espaço à italiano, apresentados ao longo do ensaio, podem servir para elucidar a afirmação de Agamben de que a profanação de um dispositivo evidencia o ponto de ingovernabilidade que está na partida e no fim de qualquer prática política.
\end{abstract}

Palavras-chaves: Palco como dispositivo. Configurações espaciais relacionais. Mediação espacial.

Spatial-temporal figure-ground relations. Finite spaces in contemporary theatre and performance

\begin{abstract}
Taking a critique of mere architectural conceptions of theatrical spaces as its starting point, this paper discusses different ways of undermining the proscenium stage as what can be called a dispositif or apparatus of perception. It discusses up to which point the perturbation, negation and disaffirmation of the italian stage, carried out through different spatial conception by the performances analysed in this paper, can serve to exemplify Agamben's afirmation that the profanation of a (political) dispositif highlights the point of ungovernability that exists at the beginning and the end of any political praxis.
\end{abstract}

Keywords: Stage as dispositive. Relational spatial configurations. Spatial mediation.

1 Originalmente publicado em Eke, Norbert Ott; Haß, Ulrike; Kaldrack, Irina. (orgs.) Bühne. Raumbildende Prozesse im Theater. Paderborn: Wilhelm Fink Verlag, 2014, p. 227 - 248. @ Wilhelm Fink Verlag, ein Imprint der Brill Gruppe (Koninklijke Brill NV, Leiden, Niederlande; Brill USA Inc., Boston MA, USA; Brill Asia Pte Ltd, Singapore; Brill Deutschland GmbH, Paderborn, Deutschland).

2 Professor de Ciências Teatrais na Johann-Wolfgang-Goethe Universität de Frankfurt/Main, e Coordenador dos Cursos de Mestrado Dramaturgismo e Comparative Dramaturgy and Performance Research. Entre suas últimas publicações encontram-se as coletâneas Theatre as Critique (2019) e Das Denken der Bühne (2019). Atualmente, é presidente da Sociedade Alemã de Estudos Teatrais.

3 Professor Doutor do Programa de Pós-Graduação em Teatro (PPGT) do Centro de Artes, Universidade do Estado de Santa Catarina (UDESC). Stephan Arnulf Baumgärtel. stephao08@yahoo.com.br

${ }^{4}$ Bolsista de Iniciação Científica (Cl) no projeto "Encenação enquanto Instalação" do prof. Dr. Stephan Arnulf Baumgärtel. 


\section{Transfigura ${ }^{5}$}

Figura 1 - Uma mulher jovem ou velha? Exemplo clássico de uma transfigura

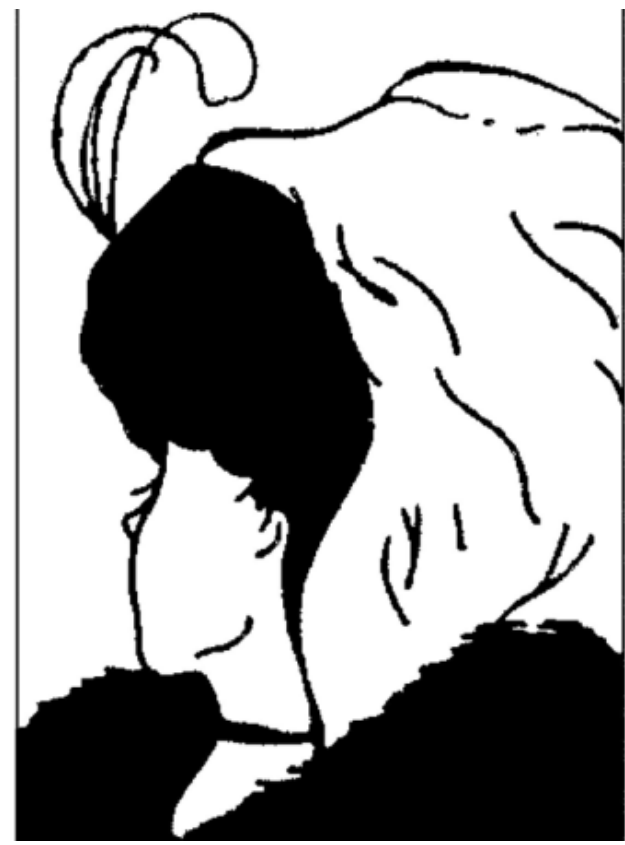

Quantos anos tem essa mulher? É com essa questão que geralmente se apresenta esta imagem. Conforme enxerguemos nela uma jovem mulher com um turbante elegante, um decote largo e um manto de pele casualmente disposto sobre os ombros, ou uma velha com olheiras e nariz adunco que, devido à sua avançada idade, está toda agasalhada, oscilaremos entre a percepção etária de 20 e poucos ou 70 e muitos anos. Mas talvez também nós, uma vez que tenhamos passado de uma imagem para outra, não possamos mais nos deter em apenas uma representação. Pelo contrário, oscilamos entre a jovem de costas e a velha

\footnotetext{
${ }^{5} \mathrm{O}$ autor usa o termo "Kippfigur" que poderia ser traduzido literalmente como "figura em processo de virada" ou "figura em queda (constante)", devido ao verbo alemão (um)kippen que significa 'virar, cair, inclinar-se até cair' e também figurativamente 'desmaiar'. Trata-se de figuras de ilusões óticas conhecidas em português também como figuras de Gestalt, seguindo a percepção de que na psicologia de Gestalt, o mundo recebe sua forma pelo olhar do ser vivente. Entretanto, Gestalt não possui o aspecto de ambiguidade e contradição de percepções presente no substantivo alemão, nem o impacto possivelmente vertiginoso. Optamos por "transfigura" para poder criar, além de uma sensação de estranheza que corresponde ao fenômeno ambíguo da imagem, o significado de uma figura em constante transformação. Importante perceber que nessa transfigura a transformação contraditória é uma possibilidade intrínseca à estrutura formal como se essa pressionasse a percepção a se dar conta dessa ambiguidade, mas é a percepção que atualiza a dinâmica no vaguear de seu olhar.
} 
que nos encara, caindo em uma espécie de visão dupla, que nos levará ainda além. Ao invés de enxergar as duas imagens, talvez percebamos o seu desenho, ou o próprio modo de nossa percepção. Em ambos casos, nos damos conta das pressuposições de imagem e percepção, um desenho de linhas inextricavelmente ambivalentes, ou uma ideia já de muitas maneiras preconcebida, que nos permite reconstruir uma imagem, ambas as imagens, ou imagem alguma. Uma transfigura nos permite ver duas figuras, uma de cada vez transfigurando-se na outra para finalmente, mediadas pela transfiguração, nos referir à figuração da própria figura, seu procedimento construtivo ou representacional.

Transfiguras não existem apenas no campo da imagem. Elas aparecem na literatura dramática na forma de heróis ambivalentes. Pensemos, por exemplo, no Ricardo III de Shakespeare, na Ifigênia de Goethe, na Lucile de Büchner em "A morte de Danton" ou no Balke em "O Achatador de Salários" de Heiner Müller. Essas figuras se encontram na filosofia, no pensamento de Walter Benjamin, mais fortemente expressas na expressão "dialética em estado de repouso" (Benjamin, 1985. p. 89). Uma formulação que ao mesmo tempo introduz a dialética, esse pensamento do movimento, como um estado de repouso, mas também aquele movimento dialético que ainda está atuando até quando encontra-se em repouso. Com isso, apresenta duas ideias opostas, que devem ser pensadas como simultâneas, mas não podem ser pensadas ao mesmo tempo. Nesse sentido, esse movimento dialético expõe a própria ideia, mais precisamente, o processo construtivo de sua apresentação, bem como o tempo e o espaço imbricados nela. Não é por acaso que Benjamin usa essa formulação pela primeira vez no contexto de seu ensaio sobre Bertolt Brecht e a desenvolve de maneira exemplar na análise do processo de construção espacial realizado pelos cartazes de Caspar Neher para a encenação d'A Ascensão e queda da cidade de Mahagonny.

Sob o título de transfiguras, eu pretendo considerar e analisar os processos formadoras de espaço no teatro e na performance que nos fazem pensar, justamente, o próprio processo de formação do espaço. Baseado na hipótese de que o palco deve ser entendido como dispositivo (conforme elaboração de Foucault e Agamben) e, dando maior atenção aos fundamentos conceituais e 
teóricos de um pensar o espaço em geral, eu abordarei especificamente a seguinte questão: como podemos abandonar a tanto caluniada quanto persistentemente reconstituída "caixa cênica"? Em contraste com dois trabalhos oriundos do campo da cena independente, quero mostrar que esse abandono pressupõe a análise do palco como dispositivo e nos exemplos que discuto está vinculado à construção de diferentes transfiguras espaço-temporais. Concretamente, quero seguir essa hipótese nos processos de criação de espaço em trabalhos de Robert Wilson, Patrizia Talacko, Mark Lammert e Wanda Golonka.

\section{No fim da época da fraude óptica: o palco como dispositivo}

Então, como falar sobre o "palco" hoje, como falar sobre o espaço? Em seu estudo O drama da visão, Ulrike Haß (2005), desenvolve o conceito de "forma cênica" para refletir sobre a combinação sistemática de ver e ser visto dentro de uma ordem, que ela compreende como paradigma de estruturas sociais que se mantém válido do século XV até o presente (Haß, 2005, p. 19). Este termo é formado em analogia ao termo "conceito de teatro ampliado" que Rudolf Münz (1998) propôs. Onde Münz inclui ao lado “(da arte) do teatro", também o não-teatro, o teatro da vida cotidiana e o teatro de rua, assim como o anti-teatro, Haß abarca além dos palcos teatrais no sentido estrito, o theatrum mundi, o "teatro" dos palcos urbanos e das festas, assim como o "não-teatro" dos palcos abstratos como, por exemplo, os da política. Se, como diz Haß e seguindo Wolfram Welsch, a "época da fraude óptica" está chegando ao fim e "sendo substituída por um modelo de intermediação e interatividade entre usuários e programas" (Haß, 2005, p. 19), surge a pergunta: como obter uma compreensão apropriada deste modelo? Minha hipótese é que, em dilatação e oposição ao modelo que Haß desenvolveu para essa época que está chegando a seu fim, o palco pode ser melhor compreendido hoje como um dispositivo. Recorrendo a Foucault, Giorgio Agamben (2008, tradução brasileira 2009) propôs recentemente um uso desse termo já corrente, que me parece útil no contexto da reflexão sobre o palco. 
Com "este termo", assim diz Foucault, ele tenta determinar "um conjunto absolutamente heterogêneo"

que implica discursos, instituições, estruturas arquitetônicas, decisões regulamentares, leis, medidas administrativas, enunciados científicos, proposições filosóficas, morais e filantrópicas, em resumo, tanto o dito quanto o não dito [...]. (em Agamben, 2009, p.28).

Foucault vê um dispositivo como uma "certa manipulação de relações de força" que estão inscritas em um jogo de poder, mas que também são ligadas aos limites do saber. "Assim, o dispositivo é: um conjunto de estratégias de relações de força que condicionam certos tipos de saber e por ele são condicionados." (Agamben, 2009, p.28).

Como desenvolvido por Giorgio Agamben a partir daqui, o "dispositivo" de Foucault com seus significados jurídicos, técnicos e militares pode ser relacionado ao conceito teológico de uma Oikonomia e acima de tudo ao Ge-stell de Heidegger. Nas palavras de Agamben: "Um conjunto de práxis, de saberes, de medidas, de instituições cujo objetivo é gerir, governar, controlar e orientar, num sentido que se supõe útil, os gestos e os pensamentos dos homens [sic]" (Agamben, 2009, p.39). Nesse sentido, o palco aparece como parte dessa classe de elementos existentes que, como diz Agamben, defronta seres viventes ou substâncias e, junto com eles constitui ativamente os sujeitos. Ele se encaixa facilmente na série longa e incompleta que Agamben elenca para além do pensamento de Foucault com seus dispositivos tais como prisões, manicômios, escolas e fábricas, o panóptico, a confissão, as disciplinas e as medidas jurídicas, na forma de escrita, literatura, filosofia, agricultura, cigarro, navegação, computadores, telefones celulares e da "própria linguagem, que talvez seja o mais antigo dos dispositivos" (Agamben, 2009, p.41). A linguagem aparece como uma cisão tão primordial quanto a da hominização, pelo meio da qual a humanidade consegue solapar seu peculiar comportamento animal, agora separada dele, e assim, enfim, desfrutar a abertura enquanto tal, o Ser/Ens enquanto SER/Ens (Agamben, 2009, p.43). A transformação do palco nos tempos recentes poderia ser entendida nesse esquema como a substituição de um dispositivo por outro. Aqui e ali, os corpos 
ganham sua identidade e liberdade através de uma série de práticas e discursos, saberes e condicionamentos. Aqui e ali é preciso lidar com uma substância que, numa luta como se fosse corpo a corpo com os dispositivos, está em vias de subjetivar-se e de dessubjetivar-se.

No entanto, o conceito de dispositivo de Agamben não pode ser aplicado sem refletir sobre uma tendência de seu argumento que é tão tentador quanto desastroso - em vista do valor cognitivo de seu conceito. Agamben descreve os dispositivos capitalistas de hoje como distintos das antigas disposições governamentais e religiosas, no sentido de que enquanto antigamente se instaurava um processo de subjetivação, hoje temos um processo de dessubjetivação, algo que lhe parece mostrar-se o mais explícito em usuários de celulares e nos telespectadores. No final de seu ensaio, influenciado tanto por um tom alarmante quanto por uma concepção subjacente da história como processo decadente, ele caracteriza a imagem do mundo atual como marcada por uma máquina girando em vão e cujo giro conduz à catástrofe. No entanto, a esse funcionar num vazio, Agamben não sabe contrapor nada além de um apelo não mais especificado de - como ele diz em sua terminologia - profanar os dispositivos, ou seja, de devolver ao uso comum aquilo que foi capturado e separado neles. A condição para realizar isso seria de que aqueles que se propõem a responder à questão da profanação estejam "em condições de intervir sobre os processos de subjetivação, assim como sobre os dispositivos, pra levar à luz aquele elemento ingovernável, que é simultaneamente início e ponto de fuga de toda política." (Agamben, 2009, p.51).

Pois, após ter constatado que os dispositivos de dessubjetivação cada vez mais difundidos fazem frente ao "corpo social mais dócil e covarde" da história da humanidade, aquele inofensivo cidadão democrata que entretanto é considerado "pelo poder como um terrorista virtual" (Agamben, 2009, p.49). A referência posicionada com efeito impactante ao "elemento ingovernável" em sua falta de especificação abre espaço para toda forma imaginável de mistificação e malentendidos entusiasmados. A este respeito, com vista à questão específica das dissociações e dos processos de subjetivação que andam de mãos dadas com os 
vários dispositivos do palco, faz-se necessária uma desmistificação, uma desintoxicação e, em última análise, uma concretização da teoria de Agamben que vá além daquilo proposto por ele - pelo menos se quisermos torná-la produtiva dentro do contexto de uma pesquisa teatral como ciência crítica.

\section{"Palco" no contexto da análise da origem dos conceitos sobre espacialidade}

O desenvolvimento do palco como dispositivo deve ser discutido hoje sobretudo no contexto da "crítica da origem dos conceitos sobre espacialidade" (Dünne/Günzel, 2006, p.12), ${ }^{6}$ que se deu em um momento de renovada atenção às condições da espacialidade. A partir do livro Postmodern Geographies, de Edward Soya (1989), ela foi rotulada como virada espacial, e sob a ótica de Sigrid Weigel (2002) como virada topográfica e sob outras como uma virada topológica.

Em sua contribuição para o debate sobre essa virada, Bernhard Waldenfels inicialmente elabora três grandes etapas do pensamento ocidental sobre lugar e espaço: Enquanto o pensamento clássico antigo giraria em torno da noção de um "cosmos", e nessa estrutura cósmica a cada ser existente seria atribuído um lugar próprio, substituir-se-ia - no processo da redução do cosmos a um mundo natural calculável - o topos cósmico e social pela estrutura vazia do spatium. Isso criaria um espaço homogêneo e isotrópico. Waldenfels evidencia que o ponto problemático dessa construção espacial, dominada pelo modelo euclidiano de espaço, "consiste em tomar um mundo como ser verdadeiro, onde, de fato, há um método." (Waldenfels, 2007, p. 71).

Não é difícil reconhecer que aqui está pré-configurado aquele dispositivo, em relação ao campo teatral, que se forma de maneira mais pura no século XIX, mas que se baseia em desenhos e modelos do período moderno inicial e se apoia nos escritos programáticos e filosóficos do século XVIII, para chegar à sua forma essencial, entretanto, somente no cinema e na televisão: o palco da caixa cênica, aquele universo cênico entre paredes, separado do mundo ficcional dos atores

${ }^{6}$ Sobre o assunto, ver também Günzel (2007 e 2009). 
pela quarta parede, realizado na arquitetura teatral em forma da cena à italiana, pelo proscênio, o portal do palco e a cortina vermelha. A impressão de realidade e até a crença de poder encontrá-la subitamente no palco, supõe, de acordo com o paradigma do spatium, que tudo o que aparece sobre o palco pode ser observado em separado, nada possui um lugar específico próprio, onde possa ser retomado, ou "um lugar comum compartilhado com outras pessoas." (Waldenfels, 2007, p.70).

Como Waldenfels ilustra em sua descrição com múltiplos exemplos, ao redor da virada do século XIX para o XX está começando uma nova maneira de pensar o espaço. Participam desse processo a teoria dos campos físicos, a topologia matemática, a teoria biológica ambiental, as teorias comportamentais das ciências humanas e sociais, a arquitetura e especialmente a fenomenologia do espaço, que retorna para experiência do espaço e do tempo em estreita integração com a fenomenologia do tempo, pegando como ponto de partida o universo vivido, no qual cada um de nós "está ancorado e que se abre para nós através de nossos movimentos corporais" (Waldenfels, 2007, p.71). A partir deste ponto surge aquele pensamento que Waldenfels denomina como paradoxo vivido, retomando o insight de Husserl sobre a "crise das ciências europeias". O paradoxo consiste em que o ponto de partida de um observador ancorado corporalmente no mundo implicaria que ele próprio possa muito bem pertencer ao espaço que ele está olhando, mas não por completo, caso contrário

o aqui seria apenas uma localização parcial de uma localização total; na ausência da distância necessária e de uma determinada diferença, o todo não seria como todo compreensível e passível a ser denominado. A fala sobre o todo se torna totalitária no momento em que ela nega de reconhecer-se como um discurso sobre o todo. (Waldenfels, 2007, p.75).

Conforme a explicação de Waldenfels, esses e muitos outros paradoxos surgem da determinação do espaço como "uma autorreferência que emerge toda a vez que a suposição de um primeiro, um último ou um todo se torna questionável" (Waldenfels, 2007, p. 76). Um estudo mais amplo dos paradoxos do espaço e dos projetos que respondem a eles teria de dialogar ao menos com a 
tradição de uma descrição espacial social, que parte de Durkheim e Simmel, passa por Lefebvre e Foucault - quem considera o século XX como a "Época do Espaço" - e se estende até aqueles que, baseados nesses teóricos estão dando continuidade a eles ou os estão revisando, como de Certeau, Augé e a atual discussão sobre a"virada espacial" [spatial turn].

Aqui queremos apontar somente os paradoxos da experiência espacial que possuem especial importância para o contexto do teatro e que são difíceis de serem aguentados tanto no contexto teatral quanto em outros contextos. Para melhor representar esse aspecto, talvez seja melhor lembrar duas das patologias espaciais de Eugene Minkowski, citados por Waldenfels. O paraplégico que para responder à pergunta "Onde você está?" aponta para o lugar em que ele se encontra, enquanto o esquizofrênico explica: "Eu sei onde estou, mas não me sinto lá” (Waldenfels, 2007, p. 80). Entretanto, nesse ponto deve-se pensar que estar aqui sempre implica não apenas estar aqui, mas ao mesmo tempo não estar em nenhum outro lugar, de forma que desta diferenciação espacial deriva uma diferenciação temporal. Nos deparamos aqui, de outra forma, com aquela diferença da representação que Derrida (1991) tentou captar através do conceito de differance. Ninguém o descreveu de forma tão sutil e com um senso tão apurado de seu impacto destrutivo como Werner Hamacher (2010) em uma curta coleção de notas e aforismos intitulados Amphora. Refletindo sobre os paradoxos da autorreferencialidade usando como abordagem os princípios de topos, lugar e espaço, Hamacher chega em uma definição lapidar que considero muito importante para as minhas próximas reflexões: "Espaços: fins" (Hamacher, 2010, p.34). Não só porque assim se descreve o processo de construção do espaço como um movimento por princípio aberto, porque espaços em sua finalização abrem para novos espaços, mas também porque aponta-se para espaços como fim ou limites, de forma que a cada momento seja inerente uma espacialização ou temporalização, uma descentralização que o afasta de si mesmo. Espaço surge como palavra para uma limitação cujos limites se perdem no infinito.

A terceira época apresentada por Waldenfels, que ainda continua nos paradoxos concebidos em termos espaciais, tem o seu equivalente nas aspirações, 
surgidas no teatro da virada do século 20, que pretendiam afastar-se da perspectiva de "imagens direcionadas a pontos de fuga", que "determinou a forma do palco do teatro europeu desde a Renascença" (Brandstetter/Wiens, 2010, p.9). Devem ser lembradas aqui as tentativas de dissolução do dispositivo caixa cênica, a luta pela sua substituição por outros dispositivos em projetos concebidos ou realizados por Craig, Copeau, Reinhardt, Piscator, Meyerhold, Blok, Maeterlinck e, acima de tudo, nas obras de Adolphe Appia, cujo desempenho e legado foram reavaliados recentemente em uma antologia intitulada Teatro sem ponto de fuga. (ver Brandstetter/Wiens, 2010).

Mas este título, que vincula a dissolução do dispositivo da caixa cênica a seu afastamento de um ponto de fuga em seu enfoque num único elemento, ainda que seja central e que mude no decorrer das reformas do palco, não deve ser compreendido como reverberação de uma abordagem com a qual as próprias contribuições do livro rompem. Uma abordagem cuja problemática pode ser reconhecida em sua total plenitude nas bem difundidas concepções do espaço cênico em Carlson, Pfister e Pavis, para citar apenas alguns exemplos. Elas diferenciam, como se fossem simples variações, diversos tipos de palco: começando com o palco da performance que circunda a plateia, chamado de “ambiental", passando pela arena e o palco frontal até o palco do cinema (ver figuras 2 e 3). Os modelos têm em comum que reduzem a formas arquitetônicas o que deveria ser avaliado como dispositivo. Pois, separam essas formas de suas estruturas e de seus contextos funcionais, ao invés de conceber essas relações como dispositivo no contexto de seu respectivo pensamento sobre o espaço e também no contexto de discursos sobre a arte da atuação, dos desenvolvimentos institucionais, de leis e regras, de doutrinas filosóficas, morais e filantrópicas, etc. Por sua vez, esses projetos são agrupados em tipos que sugerem uma compreensão histórica, mas que na verdade não passam de uma projeção da concepção atual de teatro para o passado, que se desconhece como tal. Isso impede que os dispositivos do passado sejam reconhecidos em sua historicidade específica. Mas essa historicidade seria nesse contexto um sugestão de termo alternativo para aquilo que Agamben provavelmente está tentando refletir sob o 
termo "ingovernável", que é o início e o ponto de fuga de qualquer política. Por último, mas não menos importante, tais representações esquecem de considerar a historicidade da própria dissociação do espaço, sua problematização no campo da filosofia desde Kant e, nas palavras do arquiteto Daniel Libeskind (2001), sua elevação a um deus negativo. A concepção do espaço enquanto uma caixa - que ela mesma já se tornou problemática na dissolução do espaço enquanto espaço vazio, realizada na terceira e última etapa de Waldenfels - subjaz nolens volens a essa representação espacial. Esse historicismo equivocado, no entanto, teve consequências no contexto das tentativas de lutar contra o dispositivo caduco, embora ainda dominante, do palco como uma caixa cênica.

De fato, a reviravolta e a associada redefinição do espaço no contexto teatral parecem mais complicadas do que sugere uma olhada para os diferentes esboços do palco em sua sequência. Esse resultado surge quando interrogamos os trabalhos cênicos atuais que, por meio de um diálogo crítico com o dispositivo da época do spatium, pretendem sobretudo atingir aquele momento do ingovernável, do qual fala Agamben no enigmático final de seu ensaio, do que esboçar uma estrutura nova.

Figura 2 - Salas de teatro, por Manfred Pfister

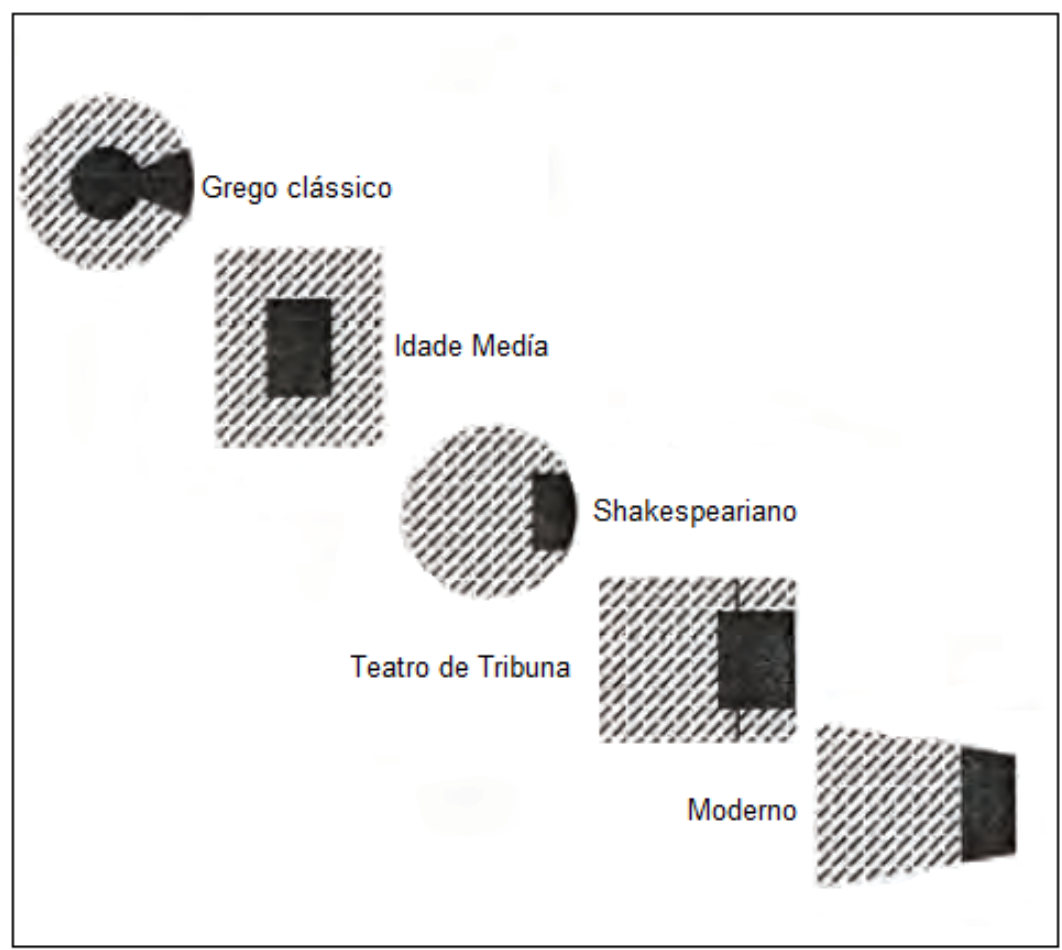




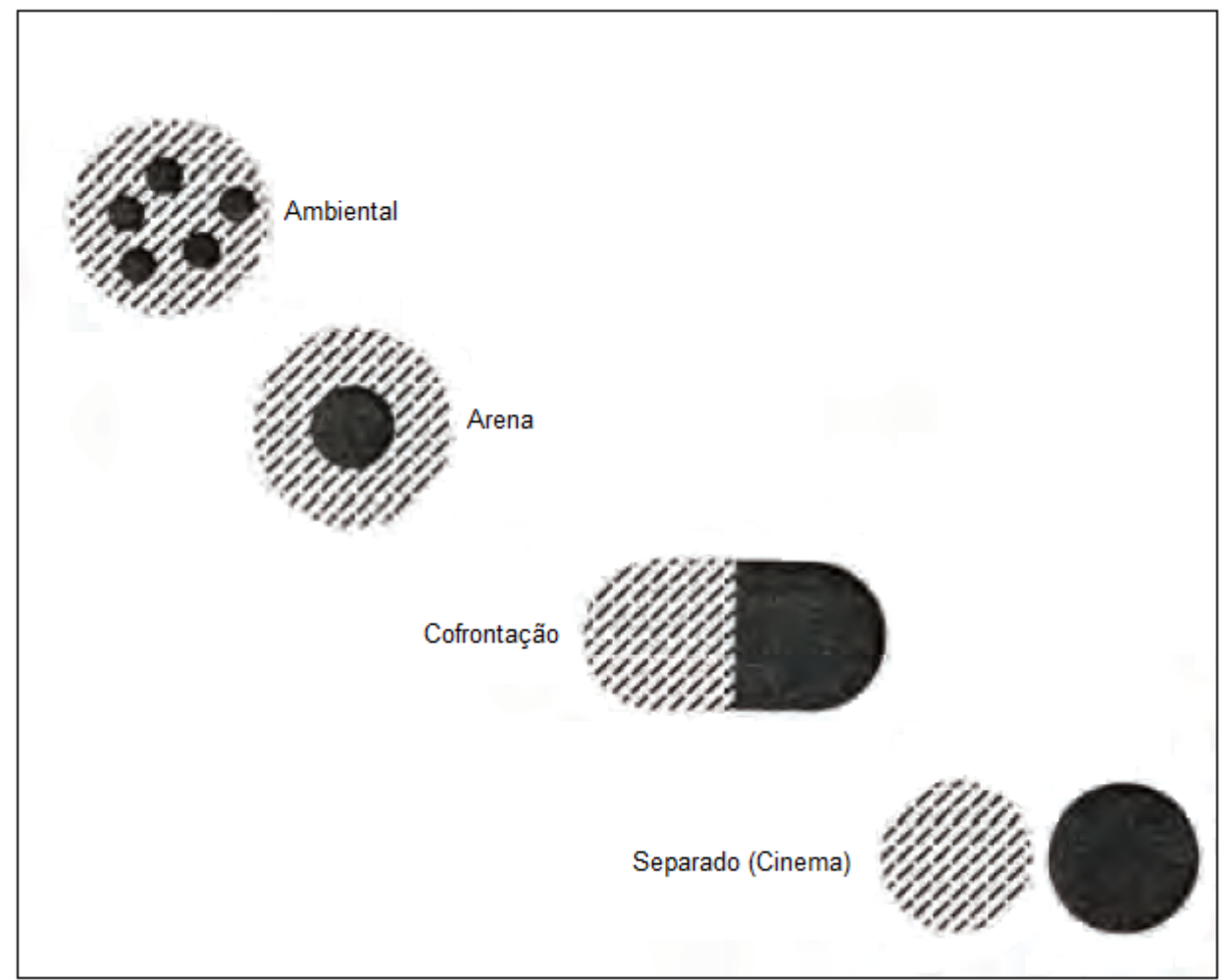

Como o dispositivo da caixa cênica (não) pode ser abandonado (Meyer \& Kowski, van Hove, Wilson)

Até hoje, as críticas sobre as práticas teatrais foram marcadas pela conclusão prematura de que as caixas cênicas e a quarta parede já haviam sido superadas, no momento em que a rampa foi extrapolada ou os espectadores foram convidados à adentrar o espaço cênico. O fato de que, por um lado, não basta dispensar a construção de um caixa cênica com ponto de fuga, e de que, por outro lado, uma organização do palco completamente de acordo com o dispositivo de uma caixa cênica pode revelar-se como uma luta contra esse dispositivo, podemos explicitar em três exemplos, que pretendo apresentar e discutir brevemente.

"O casal de atores Jörg e Susanne convida-te para dentro da cozinha deles. Eles falarão sobre suas experiências com a monogamia enquanto preparam 
iguarias japonesas para o público."7. Assim, por email, o visitante é convidado para uma noite da dupla de diretores Meyer \& Kowski, também conhecidos como Susanne Reifenrath e Marc von Henning. O endereço do convite remete a um velho galpão de um quintal sombrio em Hamburg-Wilhelmsburg, onde há um loft decorado com bom gosto. Os pouco mais de 20 convidados sentam-se numa longa mesa de madeira, em sofás ou em cadeiras improvisadas. Jörg e Susanne nos receberam, tiraram-nos nossos casacos, forneceram-nos pantufas e nos fotografaram. Agora estão de pé atrás do balcão da cozinha e começam a cozinhar. Se num primeiro momento os nossos convites e entradas nos causaram a dúvida se estávamos ali convidados para estar com Jörg e Susanne para ouvir as histórias de suas experiências, ou se tudo se tratava de estar num espaço pensado para receber os dois personagens fictícios Jörg e Susanne, em poucos minutos, ou melhor, segundos, isso foi revelado. Assim que eles começam a conversar enquanto cozinhavam, entendemos que havia dois atores à nossa frente. Se ainda não fosse possível atribuir as vozes treinadas ao fato de que são atores que nos contam a sua história, os deslizes de língua demasiadamente habilidosos, suas ocupações espaciais, o timing das piadas e a dramaturgia rapidamente reconhecível aparentam, após um breve período de tempo muito bem calculado, que tudo só poderia fazer parte integral de uma encenação. Exatamente aquilo, que eles trouxeram para a noite como arte e treinamento, exatamente o que lhes permite cumprir sua tarefa como atores, mesmo nesse tipo de enquadramento estranho, reposiciona seu jogo realizado nesse contexto como uma atuação conforme o dispositivo da caixa cênica.

Não foi diferente com a estreia razoavelmente espetacular de uma peça alemã intitulada Faces, a partir do filme homônimo de John Cassavetes. Os espectadores, desta vez, foram convidados, no contexto do festival Teatro do Mundo em Stuttgart, a entrar num grande depósito, onde ficavam numerosas camas de casal, nas quais os espectadores se sentavam ou deitavam em duplas ou trios durante a cena. Junto ao público, o conjunto do Hamburger 
Schauspielhaus, dirigido por Ivo van Hove, representou o drama da relação como se os espectadores não estivessem lá, ou tão distantes como em qualquer outra noite de uma apresentação. Mesmo quando um espectador tentava se fazer presente, este recebia em troca um olhar vazio que não the percebia.

O que ambos os exemplos ilustram, entre outras coisas, é que uma mudança no ambiente dos atores e espectadores, uma disposição diferente no espaço ou mesmo a substituição de um palco construído de acordo com regras clássicas por si só não é suficiente para abalar o dispositivo tradicional do teatro. Tal dispositivo é reproduzido por meio de instituições, de regras não somente de uma ordem supostamente artesanal ou técnica, mas de fato também social e histórica, de códigos que conectam atores e espectadores, e também pelas atitudes incorporadas nos atores. Em outras palavras: o que se torna visível nos comportamentos dos atores é, antes de tudo, sua constituição enquanto sujeitos em conjunção com um dispositivo que ultrapassa sua mera manifestação visível. Percebe-se seu habitus como ele determina a formação espacial mais do que é por ela determinado.

No que diz respeito ao teatro, Brecht talvez tenha sido o primeiro a apontar, no contexto de sua considerações sobre a peça didática, que as atitudes moldadas pela necessidade são as que sobrevivem a perda da necessidade e continuam moldando as ações dos atores. Em uma nota extraída das reflexões sobre a "grande pedagogia", à respeito de um fragmento de Fatzer, lê-se: "Nossa atitude vem de nossas ações, nossas ações vêm da necessidade. / se a necessidade é colocada em ordem, de onde vêm nossas ações? / quando a necessidade for colocada em ordem, nossas ações vêm de nossa atitude” (ver Steinweg, 1976, p. 47). Essa observação pode ser transferida do contexto mais restrito da teoria das peças didáticas para o da questão de como lutar com um dispositivo. Isso nos leva a compreender porque a moda - tão querida por um teatro alternativo - de abandonar os edifícios teatrais, a busca por fábricas, pedreiras e áreas urbanas, muitas vezes não tem conexão alguma com um questionamento do dispositivo da caixa cênica. 
Uma outra discussão desse dispositivo caduco, à primeira vista o reproduz num aperfeiçoamento raro de ser encontrado hoje em dia. Na já lendária produção de Robert Wilson de Hamlet Máquina, de Heiner Müller, o palco é tratado, conforme a concepção do século XVIII, como uma configuração espacial, mas ao mesmo tempo de acordo com a lógica de uma pintura sobre um material firme, como uma espécie de tableau vivant que se constrói no decorrer da cena em movimentos lentos e estilizados. Conforme o lema uma vez formulado por Wilson (1992, p.104) de que a trilha sonora e a imagem de uma produção devem formar um contraste, para abrir espaços de imaginação além dos limites do que o público vê e ouve, o movimento não ilustra o texto, mas segue uma lógica própria que não pode mais ser explicada. Nós vemos três mulheres em uma mesa, em frente a elas uma outra mulher postada em uma cadeira de rodas, e no decorrer da cena, mais uma série de outros atores, que entram em determinadas poses para assim ficar no palco até o final da cena, alguns com movimentos repetidos e fixos, outros com um leve tremor pelo esforço de manter o movimento. Depois segue uma cena de transformação da cenografia, feita com o palco aberto, silenciosa e banhada por uma luz branca e brilhante, durante a qual os atores - não mais em um movimento estilizado, mas sim semelhante ao que fazem normalmente os trabalhadores/auxiliares de palco - viram a disposição dos acessórios cênicos em 90 graus, enquanto um ator imóvel continua olhando para o público como se marcasse o limite da cena de transformação que acontece atrás dele. A rotação de 90 graus de um conjunto que, além disso não é modificado, é sublinhada por uma lona branca exposta - como se fosse o pano de fundo da imagem que se forma na frente dela - que na primeira cena silenciosa limita o palco do lado direito, para na segunda cena formar o pano de fundo do palco, a cena em que ouvimos o texto da primeira cena de Müller. Ou seja, depois de mais uma pausa para transformar o palco, a lona limita durante a segunda cena do texto o cenário pelo lado direito, para chegar mais tarde, depois de mais duas rotações do palco, novamente ao lado direito.

O que Wilson expõe dessa forma nessas quatro transformações diante dos olhos do público é um processo de formação de espaço, que apresenta o que 
poderia ser chamado de cenografia, ou seja, o tableau vivant no sentido do século 18, como início e ponto final de uma sequência de movimentos que são apresentados juntos com ela. Em vez de uma cenografia pronta, vemos o grafar da cena. Mais do que isso, a ação em cena não é outra coisa que o processo de formação desse espaço. Se Heiner Müller (1992, p.332) enfatizou acerca do teatro de Wilson que the interessava o momento entre um olhar e outro - "o que e como você [alguém?] vê durante o piscar?" - , este interesse se concretiza na encenação de Hamlet Máquina na qual Wilson nos permite ver algo que não víamos na construção anterior do espaço, através do giro quádruplo do palco em 90 graus que não altera os demais processos coreográficos constantes. Desta forma, ele desconstrói a suposta imagem, bem como o suposto espaço da cena, partindo daquilo que deve desaparecer no processo de sua manifestação enquanto força de formação espacial. Se Müller (1992, p.331) ainda vê Wilson como um artista visual "com a visão oblíqua" ("O poder não vem da perspectiva central, e sim da causalidade deslocada"), é possivvel complementar acerca da encenação Hamlet Máquina que essa trabalha dentro do dispositivo da perspectiva central para o esgotamento desse espaço moldado por ele. O princípio que segue esta encenação pode ser descrito, parece-me, de acordo com a definição desenvolvida no início de uma transfigura espaço-temporal: O palco, que foi inclinado quatro vezes, nos apresenta diante dos olhos o cenário construído a partir de quatro lados e em sua totalidade o aspecto inevitavelmente parcial de qualquer tipo de encontro com uma coreografia no espaço; uma ausência, que não é nem uma mera falta e muito menos algo negativo em si. É uma especificação, por meio da técnica cênica, do que Agamben descreve no final de seu ensaio como o "ingovernável" em todos os dispositivos. Aquilo que precede o dispositivo e sobrevive a ele; o resto, que existe junto com ele na sua origem e que revela a incomensurabilidade daquilo que é vivo com qualquer de suas formas de administração. 


\section{Caixa-cênica exposta - Patricia Talacko / Mark Lammert}

Figura 4 - Heiner Müller, Philoktet, Nationaltheater Mannheim, 2002. Direção: Laurent Chétouane; Cenografia: Patricia Talacko

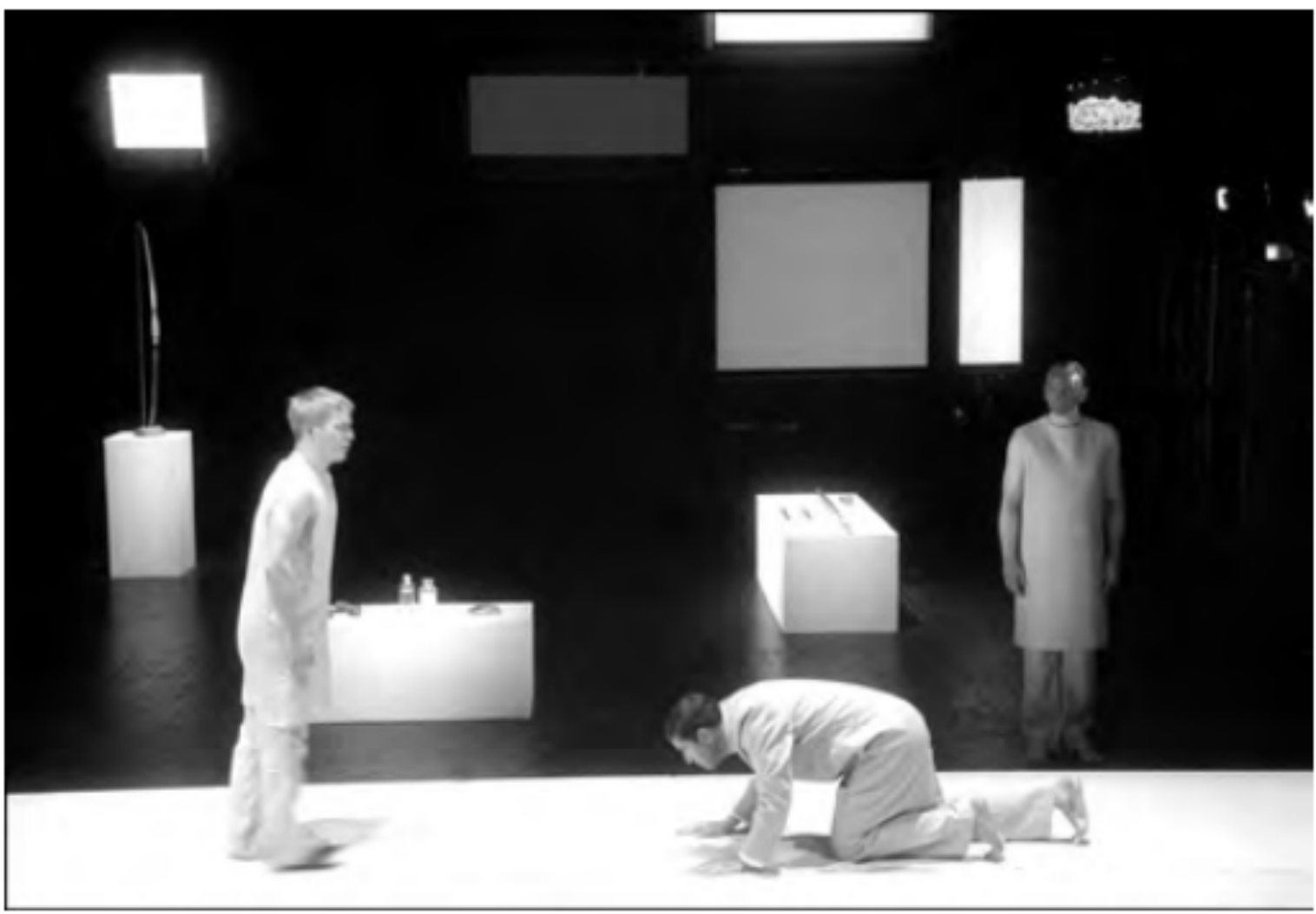

De maneira menos espetacular que Wilson, Patricia Talacko e Mark Lammert também expõem a caixa cênica como enquadramento da montagem em suas produções baseadas em um texto de Heiner Müller. Na cenografia de Patricia Talacko para a encenação de Philoktet de Laurent Chétouane, em 2002 em Mannheim, o próprio palco é um espaço de exposição no qual arcos e flechas são dispostos como em um museu (ver Figura 4). Os três atores da peça interagem uns com os outros apenas na medida em que tornam o texto audível - como texto que, por assim dizer, passa por eles; como texto que vem de outro lugar; que não pertence a eles e que ao mesmo tempo, na configuração que os três atores the dão, apresenta um conflito inextricável no contexto do jogo ficcional - e que apresenta isso num primeiro momento apenas aos três atores em cena. Para o 
público, o limite do palco é tão imperceptível que eles quase poderiam esquecêlo, mas para os jogadores ele não pode não ser notado: uma gaze, quase irreconhecível nas fotos, os separa do público e, quando o palco se ilumina faz com que o público literalmente desapareça. O jogo de Müller é assim entendido na tradição em que surge: na tradição das peças didáticas de Brecht. Como um jogo apenas para os jogadores, sem espectadores - e o rumo que Müller dá às peças didáticas consiste não por último na decisão de expor o potencial não realizado dessa forma por meio do recurso de que a apresentação sem público acontece em frente a um público, que entretanto, de certa forma, não é o públicoalvo. O público está apenas presente, mas tem tão pouco a dizer aqui quanto as pessoas lá fora na suposta democracia que as invoca como seu fundamento. Igual à encenação de Chétouane, o palco de Talacko demonstra claramente este momento no desenvolvimento da peça didática: projetada com vistas à primeiera revolução supostamente iminente e a futuras revoluções permanentes adicionais, a peça didática aparece como composição de um jogo que exibe a utopia não realizada de modo negativo, na medida em que aparece aqui no estágio de sua musealização. Como espectador, vemos, por assim dizer, em uma vitrine, os conflitos de um tempo passado; inversamente, a caixa cênica assim exibida é literalmente transformada em uma gaiola para os atores-jogadores, e seu comportamento de serem atores-jogadores é evidenciado para eles a cada momento pela parede impenetrável. A quarta parede, precisamente porque não é mais uma mera convenção, continua a aparentar uma afirmação arbitrária e uma autolimitação da cena, como parte de um dispositivo que é colocado em jogo por meio do próprio jogo cênico e de sua negociação no teatro. Isso será explicitamente tematizado em cena mais tarde, quando no final da peça, o moribundo Philoktet correndo, bate contra a gaze que o separa da plateia. A lógica do material, assim como a da peça e de seu estilo de jogo-atuação, colide nesse momento com a lógica do teatro, que em cada momento é exposta para o atorjogador mas para os espectadores provavelmente apenas naquele momento em que reconhecem, por causa da corrida do ator até o limite do campo de atuação, o que antes ignoravam: que foram separados da ação no palco o tempo todo por uma parede não apenas imaterial. Como no caso de Wilson, também aqui a 
construção de uma transfigura faz com que, por meio da formação espacial, a atenção se desloque da ação apresentada à ação de apresentação e, em particular, ao que permite essa apresentação ${ }^{8}$ acontecer.

Figura 5 - Heiner Müller, Philoktet, Théâtre de la Ville, Paris.

Direção: Jean Jourdheuil; Palco: Mark Lammert

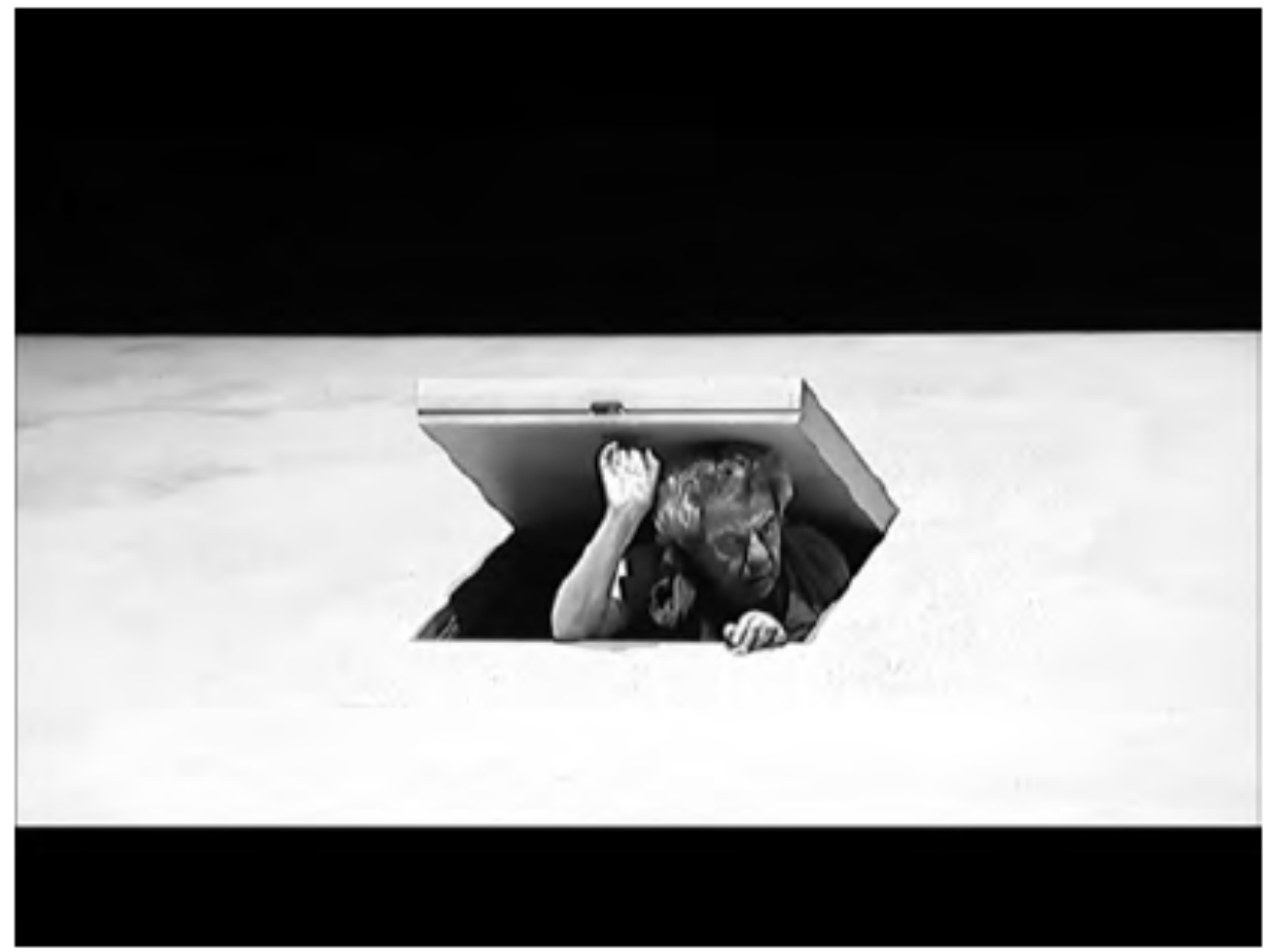

À sua própria maneira, Mark Lammert também ilustra isso por meio de sua configuração espacial, realizada para uma encenação diferente de Philoktet, a de Jean Jourdheuil em Paris e Estrasburgo (2009/2010). Em um palco vazio e escuro, há uma caixa quadrada, obliquamente ascendente, no meio da qual encontra-se uma tampa fechada. A caixa é mantida numa única tonalidade e carrega os contornos de um céu nublado: azulado e branco. No começo ela serve como a

8 O autor faz um jogo de palavras e sentido com as palavras alemãs "Vorstellung" e "vorstellen" que significa "imaginar" ou "representar mentalmente", mas no contexto de uma cena também "Apresentação" e "apresentar" respectivamente. Dessa maneira, evoca a relação entre a exposição da ação de apresentar algo como precondição da exposição do trabalho da imaginação no contexto da apresentação cênica. 
mesa onde Ulísses projeta o plano para a operação no decorrer do qual se deve persuadir Philoktet a entregar o arco de Héracles e levar o herói expulso de volta ao exército grego. Dessa maneira, Lammert insere na cena uma espécie de segundo palco que é deslocado em sua perspectiva. É um palco cuja inclinação nos permite ver a cena também de cima e não somente de frente. Com cada mudança no enredo da peça, muda também a forma como a caixa é utilizada. Ela pode ser usada para sentar em cima dela, para passar por cima dela. Quando Philoktet surge de dentro da tampa da caixa (veja a fig. 5), ela se torna a sua morada. Quando Philoktet mais tarde se senta ou fica em pé sobre ela, ela aparece como a ilha que o destino de Philoktet the fez habitar. Quando vira, vemos dentro da caverna de Philoktet. Em todo caso, é esta caixa que marca, por assim dizer, os cortes na encenação.

Em cada nova virada da peça, os atores encontrarão uma nova maneira de jogar com ela. Ela se torna assim reconhecível, em seus significados mutáveis, como uma transfigura espaço-temporal versátil. A ação se desenrola envolvendose num jogo com a caixa. Mas ao mesmo tempo, e após todas essas repetidas mudanças, ela aparece como aquilo que permanece externo aos processos espaço-temporais mesmo que os condicione. Revela neles um outro plano, próprio à caixa, e que marca neles o espaço e o tempo da apresentação cênica como algo a ser distinguido do espaço e tempo apresentados. A encenação de Jean Jourdheuil ressalta este aspecto ao fazer o intérprete do Philoktet recitar o prólogo que precede à peça de Müller no meio da encenação, de dentro da caixa que naquele momento está aberta ao público. Semelhante ao texto dirigido ao público "dos dias atuais" que é atribuído ao "ator do Philoktet, em máscara de palhaço" (Müller, 1988, p. 7), a direção de Jourdheuil então conduz o olhar para a escultura espacial de Lammert, que se torna reconhecível como mise en abyme, como uma adição comparável à máscara, que nos apresenta a caixa cênica de uma só vez como uma totalidade e exatamente através dessa adição, dissolve, muda, interrompe essa totalidade. Igual ao espaço de apresentação de Talacko, a mise en abyme de Lammert também apresenta o dispositivo da apresentação, só que aqui à apresentação corresponde uma distorção, um ato de cesura. 


\section{Esculturas espaciais - Golonka}

Com uma radicalidade que quase nenhum outro diretor e coreógrafo dos últimos anos possui, Wanda Golonka explorou o dispositivo do palco em suas produções com transfiguras espaço-temporais, exibindo e redefinindo o palco em cada caso. Assim, em Rrrungs! Uma exploração espacial na Volksbühne em 2010, ela guiou o público em pequenos grupos através do hall, passando pelo pátio e pelas escadas do edifício, por trás, para o palco enormemente volumoso, e de lá para o auditório reformado e ainda não totalmente descoberto, para desenvolver a coreografia dessa noite numa sequência de fragmentos da história que talvez seja uma das mais carregadas de história do teatro de língua alemã. Uma noite que em sua apresentação nos fez ver todos os contextos e condicionantes que essa e todas as outras noites nesse teatro específico possuem. Da mesma maneira, ela trabalhou em cada produção, ou seja, em todas as performances, peças teatrais e peças de dança realizadas nos anos anteriores no Schauspiel Frankfurt, expôs aquilo que está lá antes da apresentação ter início. As encenações For Sale e An Antigone (Frankfurt, 2003) levaram os espectadores para lugares do teatro, que em outra ocasião permaneceriam fechados para eles, para o urdimento, para os longos corredores e escadas sinuosas, para a sala de pintura e para o armazém. Ou ainda, ela usava o palco atrás da cortina de ferro móvel de uma maneira que não era prevista: em sua produção de Psychosis 4.48 (Frankfurt, 2002, ver Fig.6) de Sarah Kane, ela instalou balanços de cordas extremamente longas e conectadas, sobre os quais os espectadores foram colocados. Assim, a fala da atriz se dava ao redor dos espectadores, entre eles, mediada pelas longas cordas de arame que fizeram com que eles sentissem as respostas físicas de todos que compartilhavam com eles os balanços. Em Ganância [Gier], a partir do material de Sarah Kane, ela usou um palco giratório como uma espécie de teatro de arena ou anfiteatro, em torno do qual a plateia sentava. 
Figura 6 - Wanda Golonka, 4.48 Psychose,

Produção do Schauspiel Frankfurt, em 2002

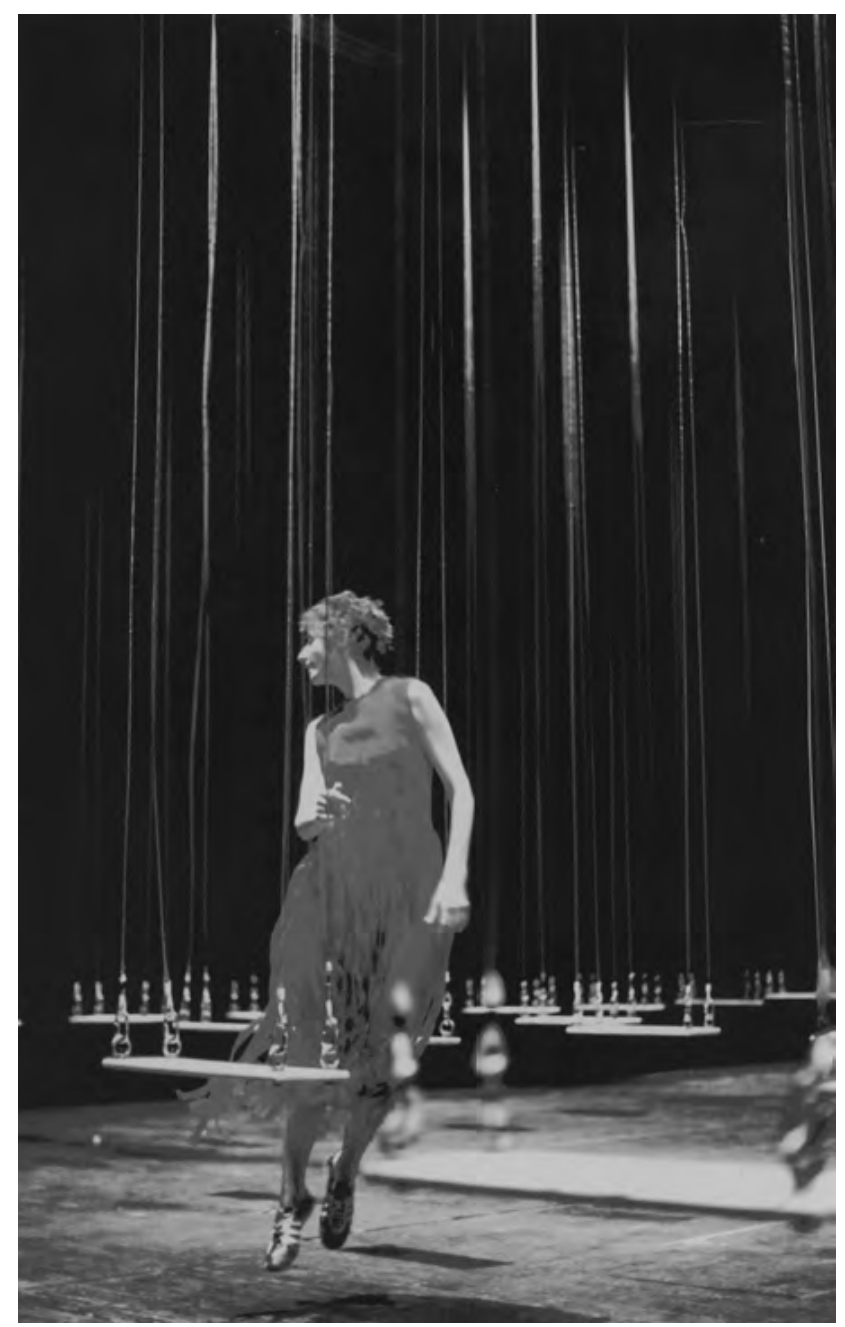

Se nesses trabalhos a transfigura surgiu, por assim dizer, através do rompimento com o uso convencional do espaço, na segunda parte da série de performance An Antigone intitulada: Se pica no ouvido, pica dentro de você? [Sticht es im Ohre, stichts im Innern dir?] desdobrou-se a transfigura espacial-temporal quando ela criou uma caixa cênica, limitada pela grande cortina de ferro, sobre o grande palco do Schauspiel Frankfurt. Nessa encenação, o público é colocado primeiro nas bordas laterais do palco, podendo assistir de lá uma mulher rasgando folhas de jornal, depois um homem (Oliver Kraushaar), que se deita em um colchão e começa a gritar um grito de partir o coração, por vários minutos. Depois de algum tempo, alto-falantes descem lentamente da urdidura. O resmungar baixo, mas 
inconfundível de alguns espectadores começa a permear um murmúrio de várias vozes, cada vez mais alto, que reconhecemos finalmente como vindo dos altofalantes. Por fim, o ator se levanta e pede aos espectadores para colocar suas cadeiras perto dos alto-falantes. Alguns espectadores dão seguimento a ação, sentam-se hesitantes no espaço, outros seguem um pouco mais tarde. Em algum momento, os primeiros se permitem deslocar de um alto-falante para outro altofalante; depois, a ordem se dissolve lentamente, a pessoa passa pela sala, deitase nos colchões sob os alto-falantes suspensos num nível mais baixo, fica de pé sob os que são colocados no alto, senta-se num círculo com outros ouvintes e escuta o som dos alto-falantes pendurados no meio do espaço, iniciam as primeiras conversas sobre a noite. Nos alto-falantes, ouve-se entrevistas com moradores de Frankfurt que foram realizadas durante as semanas de ensaio.

Como na adaptação de Golonka de 4.48 Psychosis, aqui também se faz com que o público se torne ciente do espaço compartilhado entre atores e espectadores. Desta vez, no entanto, muda a linha entre a atuação e o espectar, quando primeiro um, depois vários e, finalmente, todos os espectadores são solicitados e colocados no espaço cênico: com certa inércia ou hesitação acontece a transição de cada um, de espectador para parte de um arranjo coreografado de observadores sendo observados no espaço da cena para depois, novamente, ser dissolvido em uma multidão [grupo] de ouvintes deslocando-se de forma desorganizada e desenvolta. A demarcação entre jogador e espectador, teatro e sociedade, que no início da performance, apesar do espaço alternativo, ainda era realizada de acordo com a convenção da caixa cênica, aparece agora, devido à transformação da performance teatral em uma instalação, como um aspecto a ser negociado e não mais algo a ser negligenciado; se mostra como parte desse dispositivo, na atuação e na observação. Ou seja, a demarcação se torna passivel à negociação, se revela como histórica. O fim da época histórica da ilusão e sua transição para outra época tornam-se uma experiência possível no decorrer da performance, por meio de seu rompimento com um dispositivo e na sua transição para outro. Por último, mas não menos importante, Golonka emprega essa ruptura de maneira diferente de Wilson, Talacko e Lammert, a saber, em um breve 
momento de incerteza, que vai da dissolução do primeiro arranjo espetacular ao uso descontraído das várias possibilidades do ouvir e que leva todas as partes envolvidas àquela beira de dispositivos conhecidos, a qual Agamben vagamente se refere como trazendo à luz o "ingovernável". Por um breve período, perguntas como: "O que fazer? Como devo agir? Será que devo agir?" pairam no ar, começo e ponto de fuga de toda a política e também dos arranjos cênicos.

\section{Conclusões}

Não é coincidência que eu tenha citado exemplos de tais produções, que debatem - para além do plano da transfigura espacial-temporal perceptível no contexto de sua cena - em muitos planos o dispositivo do teatro que as antecede, o arranjo constitutivo, que sujeita todos os agentes envolvidos e molda a encenação como um todo. O que distingue a forma específica da transfigura - e que, à título de exemplo, pude aqui mostrar somente em trabalhos de Wilson, Talacko, Lammert e Golonka - é que ela é uma reflexão crítica sobre determinadas maneiras de supostamente fugir das forças coercivas da instituição, mas que de fato apenas substituem um dispositivo por outro.

A característica dos exemplos de transfiguras espaço-temporais escolhidas aqui é, por outro lado, que elas, ao referenciar o processo de formação do espaço, permitem que se possa experimentar a finitude de espaços e a maneira como os espaços chegam a um fim; que levam a uma fronteira ou um momento limiar, onde vem à tona - conforme reflexões de Agamben - o ingovernável em cada dispositivo. Há bons motivos para chamar este momento em uma outra terminologia também de experiência da medialidade (Müller-Schöll, 2002, p. 73 106). O que se experimenta aqui, é a simultaneidade de origem de qualquer governabilidade, tal como o dispositivo a consegue, e de uma ingovernabilidade constitutiva, que no momento da criação do dispositivo e dali em diante aspira opor-se a essa fundação e que trabalha para sua dissolução. Por tanto, cada uma das transfiguras discutidas aqui pode, portanto, ser entendida também como a busca pela cesura de-constitutiva do próprio meio; compreendendo a palavra 
cesura no sentido elaborado por Hölderlin como um conceito de historicidade. "Uma cesura seria o que interrompe a história no meio da história e abre outra possibilidade histórica, ou fecha qualquer possibilidade de história.", como explica Philippe Lacoue-Labarthe (1990, p. 72) lucidamente essa ruptura. Nas transfiguras espaço-temporais abre-se, no interior do arranjo constituído, o olhar sobre o próprio modo de arranjar, e simultaneamente, o olhar sobre sua configuração espacial constitutiva e sobre aquilo que por meio dela era limitado e libertado. Devemos ver nisso sua política inerentemente radical, até mesmo revolucionária. Em outras palavras, abre-se a possibilidade de outro palco; o espaço e o tempo de um palco do outro.

\section{Referências}

AGAMBEN, Giorgio "O que é um dispositivo?" In: AGAMBEN, Giorgio. O que é o contemporâneo e outros ensaios. Chapecó: Argos, 2009.

BENJAMIN, Walter. "O que é o teatro épico?" In: BENJAMIN, Walter. Obras Escolhidas, vol. 1. (Magia e técnica, arte e politica), São Paulo: Editora Brasiliense, 1985. p. 89.

BRANDSTETTER, Gabriele/WIENS, Birgit (Hg.), Theater ohne Fluchtpunkt. Das Erbe Adolphe Appias: Szenographie und Choreographie im zeitgenössischen Theater, Berlin, 2010, S. 9.

DERRIDA, Jacques. "A Diferença”, In: DERRIDA, Jacques. Margens da Filosofia. Campinas: Papirus, 1991.

DÜNNE, Jörg/GÜNZEL, Stephan. Raumtheorie. Grundlagentexte aus Philosophie und Kulturwissenschaften, Frankfurt/M.: Suhrkamp, 2006.

GÜNZEL, Stephan (ed.), Topologie. Zur Raumbeschreibung in den Kultur- und Medienwissenschaften, Bielefeld: Transcript, 2007.

GÜNZEL, Stephan. (ed.) Raumwissenschaften. Frankfurt/M.: Suhrkamp, 2009.

HAMACHER, Werner. "Amphora", In: SCHWEEGER, Elisabeth (ed.) Wanda Golonka - Tanz Ensemble Modell. Berlin: Theater der Zeit, 2010; p. 29-34.

HAB, Ulrike. Das Drama des Sehens. Auge, Blick und Bühnenform, München: Fink, 2005. 
LACOUE-LABARTHE, Philippe. Die Fiktion des Politischen. Heidegger, die Kunst und die Politik. Stuttgart: Edition Patricia Schwarz, 1990.

LIBESKIND, Daniel. "Das Ende vom Raum - ein Gespräch mit Gerhard Ahrens", in: Hamburger Hefte, Nr. 4, raumgestalten, Hamburg, 2001, p. 42-51.

MÜLLER, Heiner. "Robert Wilson/Freunde“, in: MÜLLER, HEINER. Krieg ohne Schlacht, Köln: Kiepenheuer \& Witsch, 1992, p. 327-336.

MÜLLER, Heiner Philoktet. in: MÜLLER, Heiner. Mauser, Berlin: Rotbuch, 1988, p. 742.

MÜLLER-SCHÖLL, Nikolaus. Das Theater des konstruktiven Defaitismus. Frankfurt/Basel: Stroemfeld, 2002.

MüNZ, Rudolf. Theatralität und Theater. Zur Historiographie von Theatralitätsgefügen, Berlin, Schwarzkopf \& Schwarzkopf. 1998, S. 82-103.

SOJA, Edward. Postmodern Geographies. The Reassertion of Space in Critical Social Theory. London \& New York: Routledge, 1989.

STEINWEG, Reiner Brechts Modell der Lehrstücke. Zeugnisse, Diskussionen, Erfahrungen, Frankfurt/M., 1976

WALDENFELS, Bernhard. „Topographie der Lebenswelt“, in: GÜNZEL (ed.), Topologie. Zur Raumbeschreibung in den Kultur- und Medienwissenschaften, Bielefeld: Transcript, 2007, p.69 - 84.

WEIGEL, Sigrid. „Zum ,topographical turn“ - Kartographie, Topographie und Raumkonzepte in den Kulturwissenschaften“, in: KulturPoetik 2, 2 (2002), p. 151165.

WILSON, Bob. "Die Architektur des theatralischen Raumes". Entrevista com Tom Stromberg. In: Theaterschrift 2. The Written Space 1992, p. 102-107.

Recebido em: 3/07/2020

Aprovado em: 3/072/020

Universidade do Estado de Santa Catarina - UDESC Programa de Pós-Graduação em Teatro - PPGT Centro de Arte - CEART 